\title{
Body Surface Area Formula for Cats
}

National Cancer Institute

\section{Source}

National Cancer Institute. Body Surface Area Formula for Cats. NCI Thesaurus. Code C68653.

The formula to calculate body surface area in cats. It is mathematically defined as: BSA $\left(m^{\wedge} 2\right)=\left(10.1 \times\right.$ Weight $\left.(g)^{\wedge} 2 / 3\right) / 1000$ 